\title{
The Improvement Effect of Enteromorpha prolifera Biochar on Chromium-Contaminated Soil
}

\author{
Xiaochen $\mathrm{Li}^{1}$ and Liqing $\operatorname{Ren}^{2, *}$ \\ ${ }^{1}$ Ocean University of China, College of Environmental Science and Engineering, 266000 Qingdao, China \\ ${ }^{2}$ Urumuqi Meteorological Satellite Ground Station, 830011 Urumuqi, China
}

\begin{abstract}
Using biochar to improve chromium-contaminated soil is a promising method. In this study, the Enteromorpha prolifera biochar was prepared at different temperatures $\left(300{ }^{\circ} \mathrm{C}-700{ }^{\circ} \mathrm{C}\right)$, and rye pot experiment was conducted to examine the improvement effect of Enteromorpha prolifera biochar on the chromium-contaminated soils. The results showed that biochar could obviously promote the growth of rye in the chromium-contaminated soil. Compared with the control group, plant height, root length and biomass were increased, with the maximum increases of $38.9 \%, 32.1 \%$ and $34.7 \%$. The chlorophyll content was increased to 2.2 - 4.6 times, and the proline and peroxidase (POD) contents were significantly decreased, with maximum decreases of $72.8 \%$ and $93.2 \%$. The Enteromorpha prolifera biochar prepared at $400{ }^{\circ} \mathrm{C}$ had a best effect on improvement of chromium-contaminated soil at the dose of $30 \mathrm{~g} \cdot \mathrm{kg}^{-1}$. The biochar effectively alleviated the stress from $\mathrm{Cr}(\mathrm{VI})$, and promoted the growth and metabolism of rye.
\end{abstract}

\section{Introduction}

With the development of industrial and agricultural production, heavy metal pollution has caused great harm to soil and water. Hexavalent chromium ( $\mathrm{Cr}(\mathrm{VI}))$ is an important environmental pollutant and biological teratogenic and mutagenic agent ${ }^{[1]}$, which has great mobility and is easy to pollute the surrounding environment and groundwater ${ }^{[2]}$. $\mathrm{Cr}(\mathrm{VI})$ has been listed as one of the eight chemical substances which are most harmful to human.

Compared with the chemical and physical remediation of chromium-contaminated soil, the phytoremediation technology is more eco-friendly ${ }^{[3]}$. While, the strong toxicity of $\mathrm{Cr}$ (VI) could cause great damage to plants to reduce the effect of phytoremediation ${ }^{[4]}$. Biochar can improve soil structure and fertility ${ }^{[5]}$ and promote plant growth. In addition, biochar is usually neutral and alkaline ( pH 5.9 - 12.3 ), with relatively high cation exchange capacity ${ }^{[6]}$. The abundant oxygen-containing functional groups on the surface of biochar could effectively fix heavy metal cations through metal precipitation, surface complexation and physical adsorption ${ }^{[7]}$, thereby reducing the content of $\mathrm{Cr}$ in the soil to alleviate the potential health risks caused by $\mathrm{Cr}{ }^{[8]}$.

The purpose of this study is to use Enteromorpha prolifera, which is abundant in Qingdao area, to prepare biochar at different pyrolysis temperatures $\left(300{ }^{\circ} \mathrm{C}\right.$ $700{ }^{\circ} \mathrm{C}$ ), so as to realize the resource utilization of waste. And through rye pot experiment, the effect of Enteromorpha prolifera biochar on the growth physiological indices of rye in chromium-contaminated soil was studied.

\section{Materials and methods}

\subsection{The experimental materials}

Enteromorpha prolifera used in the experiment was purchased from Ocean University of China Biotechnology Co., Ltd.

The test soil was collected from the topsoil $(0-20 \mathrm{~cm})$ near the chromium slag storage site of Hongxing Chemical Plant in Licang District, Qingdao. After natural air drying, ground and sieved through a $2.5 \mathrm{~mm}$ sieve and stored at room temperature. The contents of total chromium $(\mathrm{Cr}(\mathrm{T})), \mathrm{Cr}(\mathrm{VI})$, organic matter, $\mathrm{pH}$ and cation exchange capacity (CEC) of the soil were $1205.06 \mathrm{mg} \cdot \mathrm{kg}^{-}$ ${ }^{1}, 109.83 \mathrm{mg} \cdot \mathrm{kg}^{-1}, 17.66 \mathrm{~g} \cdot \mathrm{kg}^{-1}, 7.68$ and $34.51 \mathrm{cmol} \cdot \mathrm{kg}^{-1}$.

\subsection{Preparation of biochar}

Enteromorpha prolifera biochar was prepared by slow pyrolysis technology. The Enteromorpha prolifera after washing, drying and grinding was placed in muffle furnace. The required temperature for preparation of biochar was set $\left(300,400,500,600\right.$ and $\left.700{ }^{\circ} \mathrm{C}\right)$. Slowly heating to the set temperature, the biochar was continuously pyrolysed for $2 \mathrm{~h}$. After the temperature of muffle furnace got to indoor temperature, the biochar was removed out of muffle furnace. The Enteromorpha prolifera biochar prepared was screened with a $0.125 \mathrm{~mm}$ sieve, cleaned twice with distilled water, and then dried in an oven at $60{ }^{\circ} \mathrm{C}$. Then, it was bagged and sealed. The

* Corresponding author: 1224199212@qq.com 
Enteromorpha prolifera biochar prepared at different temperatures were labeled as $\mathrm{BC} 300, \mathrm{BC} 400, \mathrm{BC} 500$, $\mathrm{BC} 600$ and $\mathrm{BC} 700$, respectively.

\subsection{Pot experiment}

$1 \mathrm{~kg}$ of contaminated soil and $\mathrm{BC} 300, \mathrm{BC} 400, \mathrm{BC} 500$, BC600 and BC700 with different dose of 0, 5, 10, 20 and $30 \mathrm{~g} \cdot \mathrm{kg}^{-1}$ were mixed well in the pots respectively. The group with the $0 \mathrm{~g} \cdot \mathrm{kg}^{-1}$ biochar dose was used as the control group. An appropriate amount of distilled water was added in every pot to maintain the soil field water capacity. After balancing for 2 weeks, every pot was sown with 40 rye seeds. The seeds were thinned one week after emergence, and 20 seedlings with the same growth status were kept in each pot. The soil field water capacity was kept constant during the period. The experimental temperature was maintained at $10-25^{\circ} \mathrm{C}$ under natural light. After 30 days of plant growth, destructive samples were taken to determine the physiological indicators of plant growth. Each treatment group was repeated for 3 times.

\subsection{Detection indices and analysis method}

The contents of chlorophyll a and chlorophyll b were determined by ethanol extraction method ${ }^{[9]}$, the proline content was determined by acidic ninhydrin colorimetry ${ }^{[9]}$, and the peroxidase was determined by guaiacol colorimetry ${ }^{[9]}$.

\section{Results and discussion}

\subsection{Effects of Enteromorpha prolifera biochar on growth indices of rye in chromium-contaminated soil}

\subsubsection{Plant height and root length}

The effect of biochar on plant height and root length of rye is shown in Fig. 1. With the increase of Enterommorpha prolifera biochar dose, plant height and root length of rye both showed an upward trend. The increase of plant height and root length of rye got more obverse with the increase of biochar dose, and the growth of rye in the groups with $30 \mathrm{~g} \cdot \mathrm{kg}^{-1}$ biochar dose was the best. When the dose of Enteromorpha prolifera biochar was $30 \mathrm{~g}^{\mathrm{kg}} \mathrm{kg}^{-1}$, the plant height and root length of rye increased by $32.8-38.9 \%$ and $22.6-32.1 \%$, respectively, compared with that without biochar. $\mathrm{BC} 400$ and $\mathrm{BC} 600$ significantly promoted the growth of rye. The results showed that biochar promoted the growth of rye and alleviated the stress of chromium on the growth of rye. Moreover, the addition of biochar in different proportions and different pyrolysis temperatures promoted the growth of rye to different degrees.

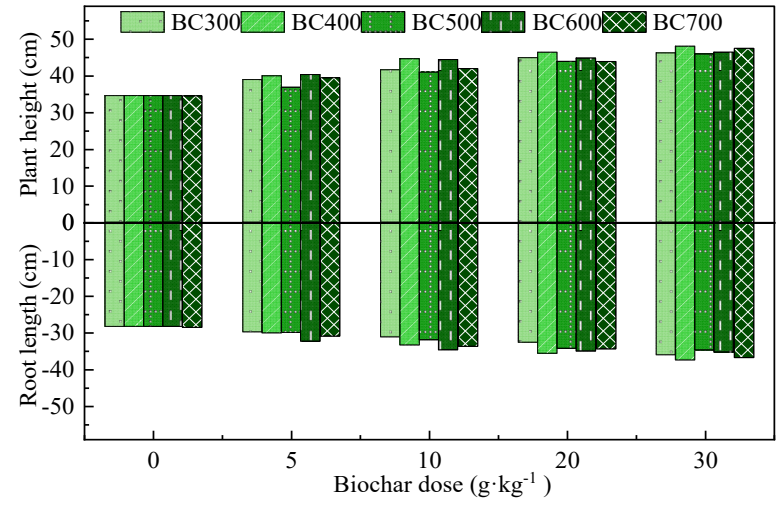

Fig. 1. Effect of biochar on plant height and root length of rye

\subsubsection{Plant biomass}

The effect of biochar on fresh weight of leaf and root of rye is shown in Fig. 2. The fresh weight of rye increased with the increase of Entermorpha prolifera biochar dose. When the dose of biochar was $30 \mathrm{~g} \cdot \mathrm{kg}^{-1}$, the fresh weight of leaf and root rose by $53.5-65.8 \%$ and $71.6-96.3 \%$, respectively. The reason might be that chromium stress impeded the metabolism of rye and reduced the biomass, while the addition of biochar alleviated the chromium stress, resulting in an increase in the biomass, and the more the amount of biochar added, the more obvious the effect. Moreover, the promoting effect of biochar on the growth of root was more obvious than that of leaf. This might because the roots had a certain trapping effect on chromium to reduce the transfer of chromium to the leaves, and when the biochar was added in soil, chromium was reduced and fixed so that the chromium stress to the roots was alleviated. Among all kinds of biochar, BC400 and BC600 increased the rye biomass most significantly, and reduced the stress of heavy metal chromium in the soil on the growth of rye.

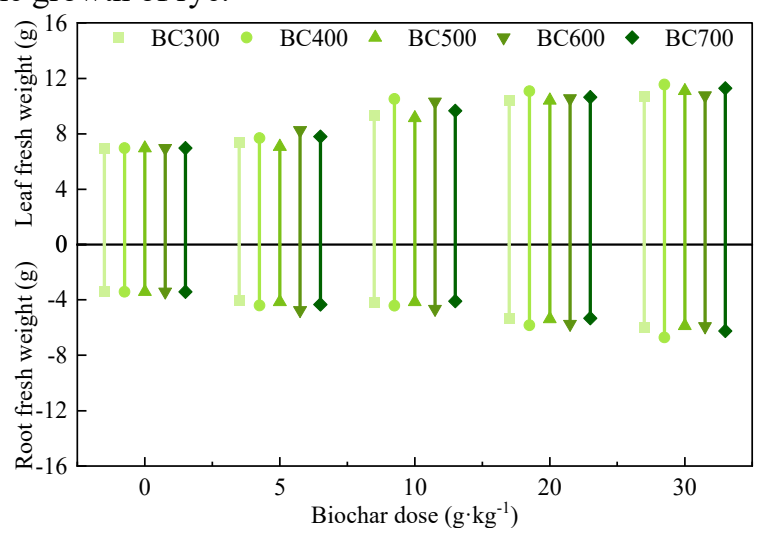

Fig. 2. Effect of biochar on fresh weight of leaf and root of rye

The effect of biochar on the dry weight of rye in chromium-contaminated soil is shown in Fig. 3. The dry weight of rye increased with the increase of Enteromorpha prolifera biochar dose. When the dose of biochar was 30 $\mathrm{g} \cdot \mathrm{kg}^{-1}$, the promotion effect was the most obvious, and the leaf dry weight and root dry weight increased by 14.5 $25.2 \%$ and $29.4-63.9 \%$, respectively. Among all kinds of biochar, BC400 and BC600 had better efforts. The leaf dry weight of rye supplemented with BC400 and BC600 
increased by $8.8-24.7 \%$ and $14.0-19.6 \%$, respectively, and the root dry weight rose by $29.7-63.9 \%$ and 32.5 $56.1 \%$, respectively, compared with the control group. The results showed that biochar had more obvious effect on the dry weight of root than that of leaf, and the addition of biochar in different proportions and different pyrolysis temperatures could promote the growth of plants to diverse degrees.

By comparing the dry and fresh weight of root and leaf, it was found that biochar was more beneficial to promoting the growth of root of rye, and the promoting effect of Enteromorpha prolifera biochar on root system was obviously greater than that on leaf. This might because the excellent characteristics of biochar could increase soil porosity, surface area, ion exchange capacity, enhance the capacity of retention of fat, which could provide a good environment for soil microbial growth and reproduction and the activity of microbes, and reduce soil nutrient leaching ${ }^{[10]}$, promoting nutrient cycle. These are the main reasons of promoting plant growth and development.

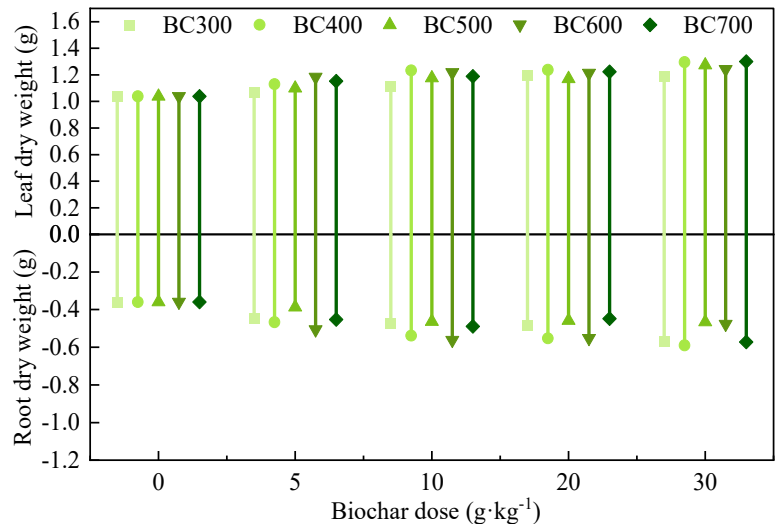

Fig. 3. Effect of biochar on dry weight of leaf and root of rye

\subsection{Effects of Enteromorpha prolifera biochar on physiological indices of rye in chromium- contaminated soil}

\subsubsection{Photosynthetic pigment}

Compared with the control group, the contents of chlorophyll a and chlorophyll $\mathrm{b}$ in rye leaf cells in all groups added with Enterommorpha prolifera biochar had an increasing trend, as shown in Fig. 4. When the dose of biochar was $30 \mathrm{~g} \cdot \mathrm{kg}^{-1}$, the promotion effort of all kinds of biochar was the most significant, and the content of chlorophyll a was 4.9 to 7.7 times that of the control group, and the content of chlorophyll $b$ was $1.7-2.0$ times that of the control group. Among all kinds of biochar, $\mathrm{BC} 400$ and BC600 had a better effort. Compared with the control group, chlorophyll a added with BC400 and BC600 increased by $4.4-6.7$ times and 3.5 - 5.6 times, respectively. The contents of chlorophyll a and chlorophyll $b$ in rye were important to the growth of the rye and were impacted by the chromium stress. The results could indicate that Enterommorpha prolifera biochar could alleviate chromium stress and reduce the toxicity of chromium.
As we in Fig. 4, when Enterommorpha prolifera biochar was applied to the soil, both chlorophyll a and chlorophyll $\mathrm{b}$ increased. The content of chlorophyll a changed faster than that of chlorophyll $b$. This might because that chlorophyll a is more sensitive to the external environment than chlorophyll $b$. This is because chlorophyll a, compared with chlorophyll b, is an important element in the primary reaction of photosynthesis. The primary reaction is extremely fast and is not affected by temperature, so it is more important for photosynthesis. The results showed that the addition of biochar could effectively reduce the stress of heavy metal chromium on rye and alleviate the damage of chlorophyll on rye leaves.

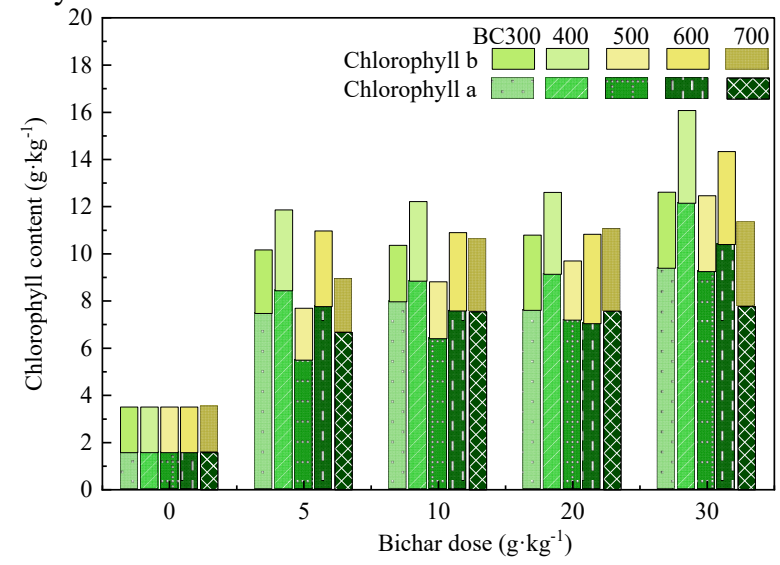

Fig. 4. Effect of biochar on chlorophyll a and chlorophyll b contents

\subsubsection{Osmotic regulation}

The influence of different kinds of Enterommorpha prolifera biochar on proline content under different dose is shown in Fig. 5. After the addition of biochar, the proline content was significantly reduced, and the decrease was more obvious with the increase of the dose. When the dose was $5 \mathrm{~g} \cdot \mathrm{kg}^{-1}$, the proline content was 2.3 5.3 times lower than that of control group, however when

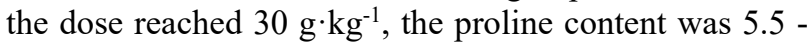
14.7 times lower than that of the control group. The proline content of BC400 and BC600 were the lowest. Proline is an important material basis for plant cytoplasmic osmotic regulation. Under stress conditions, the content of proline in plants will significantly increase to protect the body from injury caused by heavy metal ${ }^{[11]}$. Wang Xiaolan et al. ${ }^{[12]}$ proved that Carex curveolus can resist $\mathrm{Cu}^{2+}$ stress by regulating the content of free proline in vivo. The results of this study showed that under the stress of chromium pollution, a large amount of proline accumulated in rye, and the proline content decreased after the addition of biochar, indicating that the biochar effectively alleviated the stress effect of chromium on rye. And the mitigation effect of all kinds of biochar got the best when the biochar dose reached $30 \mathrm{~g} \cdot \mathrm{kg}^{-1}$. BC400 and BC600 had the best mitigation effect among all kinds of biochar. 


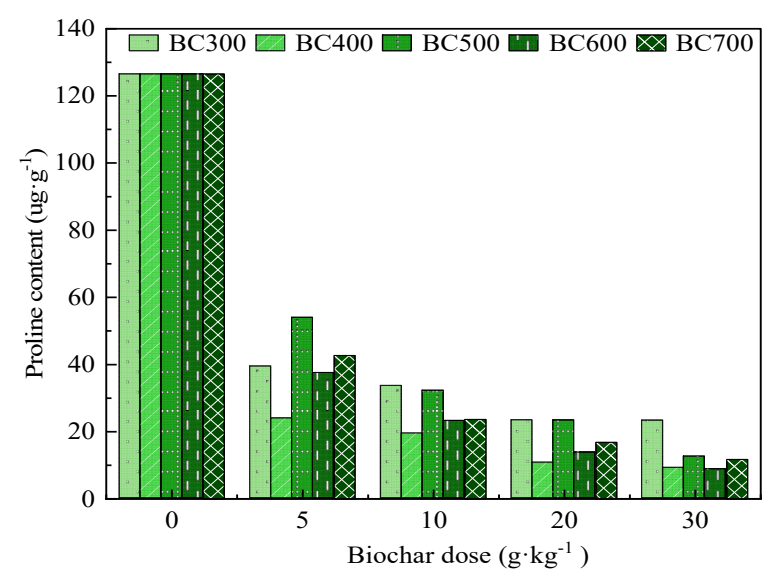

Fig. 5. Effect of biochar on proline content

\subsubsection{Photosynthetic pigment}

Peroxidase (POD) is one of the key enzymes in the plant antioxidant protection system, and it has a good protective effect on plant cells ${ }^{[13]}$. When rye is stressed by chromium, plant cells can produce more POD to protect themselves and reduce various damage caused by heavy metal chromium $^{[14]}$. The effect of Enterommorpha prolifera biochar on POD content is shown in Fig. 6. With the increase of biochar dose, POD activity showed a downward trend and the decrease of POD content was more obverse with the increase of biochar dose. When the biochar dose was $30 \mathrm{~g} \cdot \mathrm{kg}^{-1}$, the POD activity was the lowest in all kinds of biochar dose, and the POD activity of rye leaves was decreased by 1.5 - 3.7 times, compared with the control group. Among all kinds of biochar, $\mathrm{BC} 400$ and $\mathrm{BC} 600$ had the best reduction effect, and the POD content of BC400 and BC600 was decreased by 1.0 - 1.5 and 1.2 - 2.4 times, respectively, These results indicated that Enterommorpha prolifera biochar effectively reduced the toxic effect of chromium on rye.

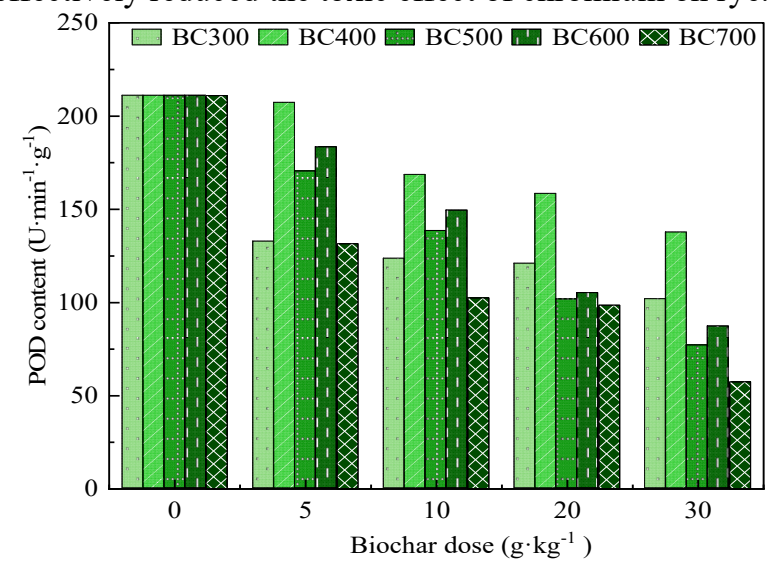

Fig. 6. Effect of biochar on POD content

\section{Conclusions}

The effect of Enteromorpha prolifera biochar on the growth and physiology of rye under chromium stress was studied by rye pot experiment. Basically have the following conclusion: the growth and physiology of rye under chromium stress were subject to a certain degree of influence. Plant height, root length, biomass and photosynthetic pigment content decreased obviously, and osmotic regulation system and antioxidant enzyme system are subjected to different degree of damage. The addition of Enteromorpha prolifera biochar significantly alleviated the toxicity of heavy metal chromium to rye, significantly increased the content of photosynthetic pigment, and significantly decreased the content of proline and POD, thus promoting the growth and metabolism of plants. The results showed that Enterommorpha prolifera biochar had obvious improvement effect on chromium-contaminated soil, and the improvement effect was more obverse with more biochar addition. Among all kinds of biochar, BC400 was the best choice, and $30 \mathrm{~g} \cdot \mathrm{kg}^{-1}$ biochar dose had the best improvement effect in $0,5,10,20$ and $30 \mathrm{~g} \cdot \mathrm{kg}^{-1}$ dose groups.

\section{References}

1. H. Zhou, G. Guo, Q. Xu, W. Gu, N. Xu, X. Zeng, X. Zhang, A. E 4, 35 (2002)

2. B. Dong, Y. Chen, H. Hui, W. Lu, X. Yang, Chin. J. Envir. Sci. 37, 4044 (2016)

3. A.P.G.C. Marques, A.O.S.S. Rangel, P.M.L. Castro, Crit. Rev. Env. Sci. Tec. 41, 879 (2011)

4. H. Luo, Z. Nan, H. Hu, C. Jin, N. Wang, Chin. J. Envir. Sci. 33, 461 (2013)

5. H.P. Jin, G.K. Choppala, N.S. Bolan, J.W. Chung, T. Chuasavathi, Plant. Soil. 348, 439 (2011)

6. S.P. Sohi, E. Krull, E. Lopez-Capel, R. Bol, Adv. Agro. 105, 47 (2010)

7. D. Filiberto, J. Gaunt, Agr. 3, 715 (2013)

8. J. Zhang, C. Ma, H. Kuang, A. Zhou, Chin. J. Envir. Sci. 37, 661 (2017)

9. M. Schallenberg, Freshwater. Biol. 53, 423 (2010)

10. H.K.S. Panahi, M. Dehhaghi, S.O. Yong, A.S. Nizami, S.L. Su, J. Clean. Prod. 270, 122462 (2020)

11. L. Szabados, A. Savouré, Trends. Plant. Sci. 15, 89 (2010)

12. X. Wang, S. Zhou, J. Yang, H. Zheng, D. Zhang, J. Agro-Environ. Sci. 29, 264 (2010)

13. G. Wang, F. Li, J. Shi, Q. Zhou, Chin. J. Envir. Sci. 34, 1579 (2014)

14. H. Lepedus, V. Cesar, M. Krsnik-Rasol, Food. Technol. Biotech. 42, 33 (2004) 